\title{
LUGOVSKOE, WESTERN SIBERIA: A POSSIBLE EXTRA-ARCTIC MAMMOTH REFUGIUM AT THE END OF THE LATE GLACIAL
}

\author{
Lyobov A Orlova ${ }^{1} \bullet$ Vasily N Zenin ${ }^{2} \bullet$ Anthony J Stuart $^{3} \bullet$ Thomas F G Higham ${ }^{4} \bullet$ \\ Pieter M Grootes ${ }^{5}$ Sergei V Leshchinsky ${ }^{6}$ Yaroslav V Kuzmin ${ }^{7} \bullet$ Aleksander F Pavlov ${ }^{8} \bullet$ \\ Evgeny N Maschenko 9
}

\begin{abstract}
Eleven woolly mammoth bone samples from Lugovskoe (central West Siberian Plain, Russia) were radiocarbon dated in 3 laboratories: Institute of Geology, Novosibirsk; Oxford University, Oxford; and Christian Albrechts University, Kiel. Each laboratory used its own protocol for collagen extraction. Parallel dating was carried out on 3 samples in Novosibirsk and Oxford. Two results are in good agreement. However, there is a major discrepancy between 2 dates obtained for the third sample. The dates obtained so far on the Lugovskoe mammoths range from about 18,250 BP to about 10,210 BP. The Lugovskoe results thus far confirm the possibility of woolly mammoth survival south of Arctic Siberia in the Late Glacial after about 12,000 BP, which has important implications for interpreting the process of mammoth extinction. The site has also produced the first reliable traces of human occupation from central Western Siberia at the Late Glacial, including unique direct evidence of mammoth hunting.
\end{abstract}

\section{INTRODUCTION}

Establishing a chronology of Pleistocene megafaunal extinctions is very important for understanding their cause(s), and placing the events in the wider context of Quaternary paleoenvironment history (Martin and Klein 1984; Stuart 1991; MacPhee 1999). A large radiocarbon data set is available for the woolly mammoth (Mammuthus primigenius Blum; hereafter, "mammoth") (Stuart 1991; Sulerzhitsky 1997; Vasil'chuk et al. 1997; Kuzmin et al. 2003). Previous research suggests that mammoths retreated at about 12,000 BP from most of its former extensive distribution in Northern Eurasia, but survived in the far north of mainland Siberia for another 2 millennia (cf. Sulerzhitsky 1997; Sher 1997). This model of spatial-temporal pattern of mammoth dynamics at the end of the Pleistocene can be called the "retreat to the north after ca. 12,500-12,000 BP" (cf. Sher 1997).

Recent research, however, indicates that mammoths were present until about 10,000 BP in the Baltic States and North Russian Plain, outside of the Arctic regions (Stuart et al. 2002: 1567; Lõugas et al. 2002). These European occurrences probably represent recolonization from the refugium in Northern Siberia during the renewed cold of the Younger Dryas phase (Stuart, forthcoming). The possibility that mammoths also survived in Siberia outside the Arctic region after 12,000 BP is very important in interpreting the process of mammoth extinction. Lugovskoe, in the central West Siberian Plain, is a key locality for the study of mammoth's late survival because it was dated to the critical period of about $12,000-10,300 \mathrm{BP} .{ }^{14} \mathrm{C}$ dates on woolly mammoth remains were carried out in $2000-2002$. Here, we present the ${ }^{14} \mathrm{C}$ results obtained so far and their preliminary interpretation.

\footnotetext{
${ }^{1}$ Institute of Geology, Siberian Branch of the Russian Academy of Sciences, Koptyug Ave. 3, Novosibirsk 630090, Russia. Corresponding author. Email: orlova@uiggm.nsc.ru.

${ }^{2}$ Institute of Archaeology and Ethnography, Siberian Branch of the Russian Academy of Sciences, Lavrentiev Ave. 17, Novosibirsk 630090, Russia.

${ }^{3}$ Department of Biology, University College London, Gower St., London WC1E 6BT, United Kingdom.

${ }^{4}$ Oxford Radiocarbon Accelerator Unit, University of Oxford, 6 Keble Rd., Oxford OX1 3QJ, United Kingdom.

${ }^{5}$ Leibniz-Labor, Christian Albrechts University, Max-Eyth-Str. 11, 24118 Kiel, Germany.

${ }^{6}$ Tomsk State University, Lenin Ave 36, Tomsk 634050; Russia.

${ }^{7}$ Pacific Institute of Geography, Far Eastern Branch of the Russian Academy of Sciences, Radio St. 7, Vladivostok 690041, Russia.

${ }^{8}$ Museum of Nature and Humans, Mira St. 11, Khanty-Mansiysk 628011; Russia.

${ }^{9}$ Paleontological Institute, Russian Academy of Sciences, Profsoyuznaya St. 123, Moscow 117647, Russia.
}

(C) 2004 by the Arizona Board of Regents on behalf of the University of Arizona Proceedings of the 18th International Radiocarbon Conference, edited by N Beavan Athfield and R J Sparks RADIOCARBON, Vol 46, Nr 1, 2004, p 363-368 


\section{MATERIAL AND METHODS}

The Pleistocene fossil mammal locality of Lugovskoe is in the modern forest zone of the central Western Siberian Plain $\left(60^{\circ} 57^{\prime} \mathrm{N} ; 68^{\circ} 32^{\prime} \mathrm{E}\right)$ about $25 \mathrm{~km}$ west of Khanty-Mansiysk City and the confluence of the $\mathrm{Ob}$ and Irtysh Rivers (Figure 1). Paleontological research has been conducted here since 1994 (Mashchenko et al. 2003). The bone bed occurs at a depth of $0.5-1.5 \mathrm{~m}$ below the modern surface within the muddy clay deposits of a small stream that flows into the Ob River. Although it is impossible to conduct proper excavations because the deposits are saturated with stream water, about 4500 fossil mammal bones were recovered in 1998-2002, of which $98 \%$ belong to mammoth. Remains of at least 27 individual mammoths were collected from the muddy clay, and several skeletal elements were found in anatomical association (Pavlov et al. 2002). Lugovskoe represents one of the richest so-called "mammoth cemeteries" in Siberia.

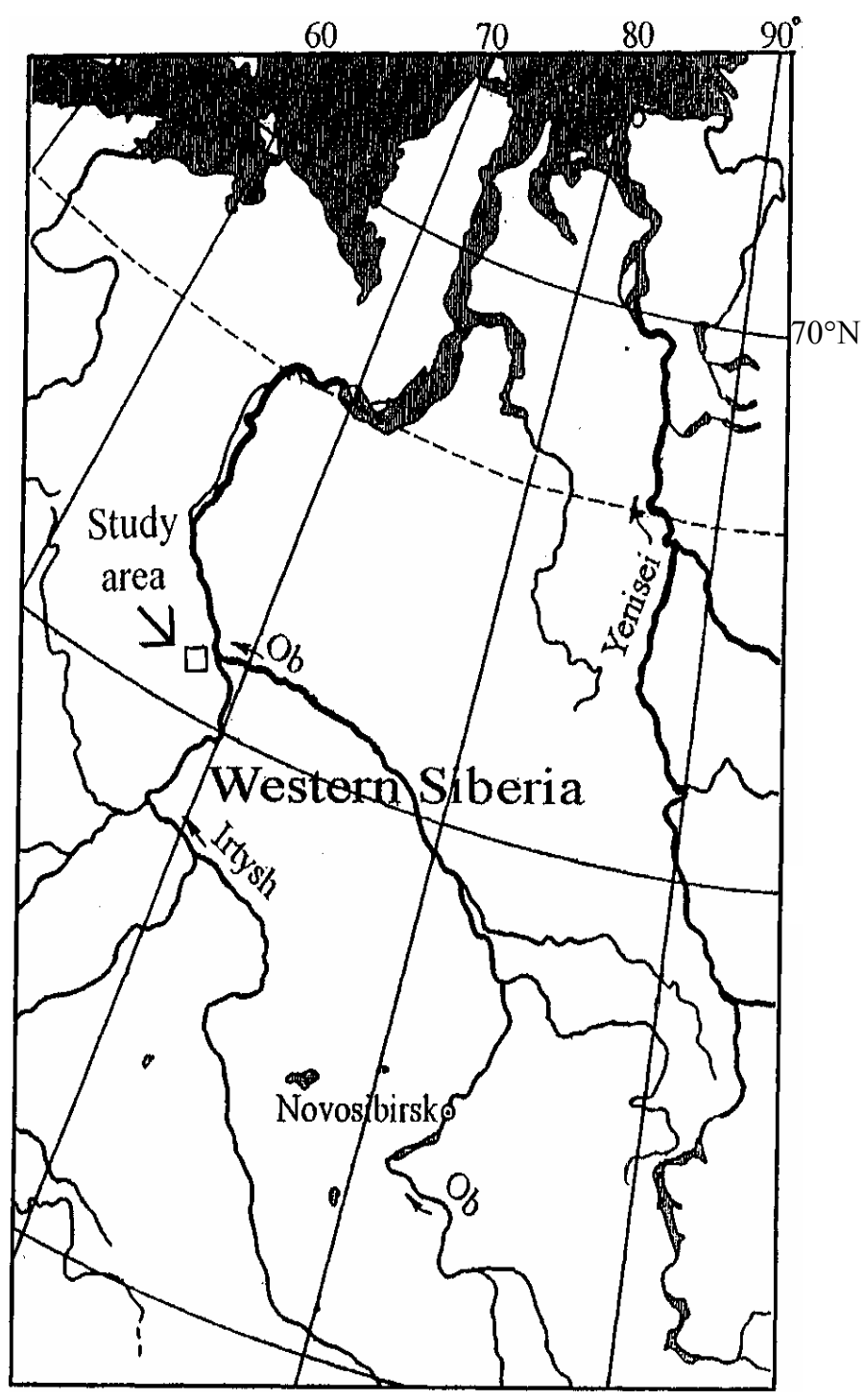

Figure 1 The position of the Lugovskoe locality in Western Siberia 
${ }^{14} \mathrm{C}$ dating of the mammoth bones was undertaken in 3 laboratories: the Institute of Geology, Novosibirsk (Russia); Oxford University, Oxford (UK); and Christian Albrechts University, Kiel (Germany). Collagen extracted from mammoth bones was dated by the liquid scintillation counting (LSC) (Novosibirsk) and accelerator mass spectrometry (AMS) (Oxford and Kiel) techniques. In each laboratory, the collagen extraction protocol is different.

In Novosibirsk, pieces of bone $10-20 \mathrm{~cm}$ long were mechanically cleaned of any surface contamination and were demineralized with a $5 \% \mathrm{HCl}$ solution (at 7-8 $\mathrm{L}$ of solution for $1 \mathrm{~kg}$ of bone) at $2-3{ }^{\circ} \mathrm{C}$. Since the process may take $1-2$ weeks, the sample is refrigerated. The extracted gelatin-like collagen was thoroughly washed with distilled water. The collagen was then treated with an $0.1-\mathrm{N}$ solution of sodium base $(\mathrm{NaOH})$ for several hours in order to remove the humic acids. The remaining collagen was again washed with distilled water, dried, and carbonized by heating in an $800{ }^{\circ} \mathrm{C}$ oxygen-free environment. To remove the phosphorous compounds, the carbonized collagen was treated with a mixture of nitric acid $\left(\mathrm{HNO}_{3}\right)$ and $\mathrm{HCl}$ ("aqua regia"). Finally, the purified collagen was washed with distilled water, dried, and used for benzene preparation and LSC measurements.

At the Oxford Radiocarbon Accelerator Unit (ORAU), bones were cleaned by scraping with a scalpel to remove soil coloration, sediment detritus, and weathered surfaces. Bone was then chemically pretreated using the ORAU continuous-flow semi-automated method (Bronk Ramsey et al., these proceedings), with an acid-base-acid sequence to isolate crude collagen, then gelatinization with weakly acidic water $(\mathrm{pH}=3)$ for $20 \mathrm{hr}$ in an incubator at $75^{\circ} \mathrm{C}$. Ultrafilters were used to isolate the $>30-\mathrm{kD}$ fraction of the bone hydrolyzate. This fraction was then lyophilized. Samples were combusted using a Europa Scientific ANCA-MS system consisting of a 20-20 IR mass spectrometer interfaced to a Roboprep CHN sample converter unit operating in continuous flow mode. Graphite was prepared by reduction of $\mathrm{CO}_{2}$ over an iron catalyst in an excess $\mathrm{H}_{2}$ atmosphere at $560{ }^{\circ} \mathrm{C}$ prior to AMS ${ }^{14} \mathrm{C}$ measurement (Bronk Ramsey and Hedges 1999; Bronk Ramsey et al. 2000).

At the Leibnitz Laboratory for Radiometric Dating and Isotope Research (Kiel), bone sample was checked and mechanically cleaned under the microscope. The collagen content was calculated from the concentration of nitrate, determined by colorimetry as nitrate in about $2 \mathrm{mg}$ of bone material. The sample was first treated with acetone, rinsed with demineralized water, and subsequently demineralized in $1 \% \mathrm{HCl}$. This was followed by $1 \% \mathrm{NaOH}$ at room temperature for $1 \mathrm{hr}$ to remove humic acids, then washed and subsequently acidified with $1 \% \mathrm{HCl}$. After filtering, the purified collagen was gelatinized overnight in $1.6 \mathrm{~mL}$ of $\mathrm{H}_{2} \mathrm{O}$ at $90^{\circ} \mathrm{C}$ and $\mathrm{pH}=3$. The gelatin solution was dried in quartz tubes, to which $\mathrm{CuO}$ and silver wool was added and combusted to $\mathrm{CO}_{2}$ at $900{ }^{\circ} \mathrm{C}$. The $\mathrm{CO}_{2}$ gas was reduced with $\mathrm{H}_{2}$ over about $2 \mathrm{mg}$ of $\mathrm{Fe}$ powder as catalyst, and the resulting carbon/iron mixture was pressed into a pellet for AMS analysis.

\section{RESULTS AND DISCUSSION}

Measurements of stable carbon and nitrogen isotopes $\left(\delta^{13} \mathrm{C}\right.$ and $\left.\delta^{15} \mathrm{~N}\right)$ were made at the Oxford Laboratory for 3 samples, OxA-12029, 12030, and 12031 . $\delta^{13} \mathrm{C}$ values are within -20.7 to $-21.3 \%$ (Table 1), and $\delta^{15} \mathrm{~N}$ values are within +4.7 to $+5.9 \%$. The collagen yield from 3 samples dated at Oxford is $1.9-4.8 \%$, which indicates poor preservation and low survival of collagen $>30 \mathrm{kD} \mathrm{MW}$. The collagen yield for 1 sample dated at Kiel (KIA-19643) was $23 \%$, about the content of a fresh bone, indicating excellent preservation. The minimum threshold for yield acceptance at Oxford is $10 \mathrm{mg} / \mathrm{g}^{-1}$ ( $1 \%$ weight collagen). Differences between the collagen yields by laboratory are liable to be a function of pretreatment method. The Oxford ultrafiltration method often produces lower yields 
in comparison with simpler bone hydrolyzate filtration methods, a fact we attribute to the removal of degraded collagen, salts, and low molecular weight particulates. The $\mathrm{C} / \mathrm{N}$ ratios for the Oxford samples ranged between 3.3-3.4, and values between 2.9-3.5 are considered acceptable (DeNiro 1985).

Table $1{ }^{14} \mathrm{C}$ dates for woolly mammoth from Lugovskoe ${ }^{\mathrm{a}}$.

\begin{tabular}{|c|c|c|c|c|c|}
\hline Lab code & Sample & ${ }^{14} \mathrm{C}$ age (BP) & $\delta^{13} \mathrm{C}(\%)$ & $\delta^{15} \mathrm{~N}(\% 0)$ & $\mathrm{C} / \mathrm{N}$ ratio \\
\hline SOAN-3838 & Tibia & $18,250 \pm 1100$ & - & - & - \\
\hline SOAN-5065 & Scapula fragment & $15,420 \pm 215$ & - & - & - \\
\hline SOAN-4940 & Thoracic vertebrab $^{\mathrm{b}}$ & $13,720 \pm 160$ & - & - & - \\
\hline OxA-12030 & Thoracic vertebrab $^{\mathrm{b}}$ & $13,455 \pm 60$ & -21.1 & +4.7 & 3.4 \\
\hline SOAN-4942 & Pelvic bone $^{\mathrm{c}}$ & $13,490 \pm 155$ & - & - & - \\
\hline OxA-12029 & Pelvic bone ${ }^{c}$ & $13,450 \pm 50$ & -20.7 & +5.9 & 3.4 \\
\hline KIA-19643 & Thoracic vertebra $^{\mathrm{d}}$ & $13,465 \pm 50$ & -21.4 & - & - \\
\hline OxA-12031 & Molar fragments ${ }^{\mathrm{e}}$ & $13,205 \pm 60$ & -21.3 & +4.9 & 3.3 \\
\hline SOAN-4943 & Molar fragments $\mathrm{s}^{\mathrm{e}}$ & $10,820 \pm 170$ & - & - & - \\
\hline SOAN-5063 & Femur & $12,970 \pm 160$ & - & - & - \\
\hline SOAN-4754 & Cervical vertebrae & $12,830 \pm 350$ & - & - & - \\
\hline SOAN-4753 & Femur & $11,840 \pm 95$ & - & - & - \\
\hline SOAN-4755 & Ulna & $11,310 \pm 380$ & - & - & - \\
\hline SOAN-4752 & Femur & $10,210 \pm 135$ & - & - & - \\
\hline
\end{tabular}

Three samples of mammoth material from Lugovskoe were submitted for parallel dating to the Novosibirsk and Oxford laboratories, both to corroborate the results and to compare the effect of different collagen extraction methods. Two out of 3 samples (SOAN-4940, 4942; and OxA-12029, 12030) are in good agreement (see Table 1), but there is a serious discrepancy between SOAN-4943 and OxA-12031. When submitted, the samples were believed to be fragments of the same tooth. The samples, represented by lamellas of mammoth tooth, were collected from mud deposits. Several lamellas were used for liquid scintillation dating at Novosibirsk. The difference in the results raises the possibility that they may have come from different individuals. Alternatively, the samples may have come from the same tooth, in which case there is a significant disagreement between the 2 laboratories. Additional mammoth samples from Lugovskoe of the putative post-12,000 BP age are being submitted to resolve this important question.

Results of ${ }^{14} \mathrm{C}$ dating of the Lugovskoe mammoths (Table 1) show that bones accumulated at the site over a long period of time, from about $18,250 \mathrm{BP}$ to about $10,200 \mathrm{BP}$. The 3 youngest ${ }^{14} \mathrm{C}$ values for the Lugovskoe mammoths $(11,840 \pm 95$ BP [SOAN-4753]; 11,310 \pm 380 [SOAN-4755]; and $10,210 \pm 135 \mathrm{BP}$ [SOAN-4752]; Table 1), are of particular importance. During the last few years, a number of mammoth dates post-12,000 BP have been reported from southern and central Siberia: Volchya Griva (about 11,090 BP), Sosva River (about 11,080 BP), and Konzhul (about 11,980 BP) (Orlova et al. 2004); and from the North European Plain: Puurmani (about 10,100-10,200 BP) and Cherepovets (about 9800 BP) (Lõugas et al. 2002; Stuart et al. 2002). The contribution of the Lugovskoe date series is that it might be one of the areas with very late mammoths which survived 
until the end of the Pleistocene, about 10,200 BP. In addition, a very late ${ }^{14} \mathrm{C}$ date for woolly rhinoceros from the Lugovskoe, $10,770 \pm 250 \mathrm{BP}$ (SOAN-4757) (Orlova et al., these proceedings) makes it one of the most important localities in terms of research on late survival of the Upper Pleistocene megafauna in Northern Asia.

One of the mammoth vertebrae has direct evidence of mammoth hunting by prehistoric humans, the single example known from Siberia so far. The mammoth thoracic vertebra, which is attributed to an adult female mammoth of about 23-25 yr old, has a cone-shaped hole resulting from the penetration of a notched point, and there are fragments of quartzite flakes lodged in the hole (Pavlov et al. 2002; Zenin et al. 2003). The vertebra has been ${ }^{14} \mathrm{C}$ dated to about 13,470 BP (Table 1).

\section{CONCLUSION}

The available evidence from Lugovskoe, and from several other localities in Siberia and Europe, confirm survival of woolly mammoth south of the Arctic region after about 12,000 BP, which has important implications for our understanding of the process of mammoth extinction. The Lugovskoe ${ }^{14} \mathrm{C}$ date series indicate that the nature of the mammoth habitat in Siberia after about 12,000 BP was quite "patchy," with few isolated populations outside of the High Arctic. This is distinct from the model of "retreat to the north after approximately 12,000 BP," which is now challenged by the new post-12,000 BP mammoth ${ }^{14} \mathrm{C}$ dates from Siberia and North Russian Plain, including the Lugovskoe. In order to test this hypothesis of extra-Arctic survival, more ${ }^{14} \mathrm{C}$ dating, including parallel dating by Russian, West European, and North American laboratories, is being undertaken. This compliments ongoing research on the chronology and paleoenvironment of mammoths and other extinct megafauna, especially in temperate Western Siberia where there may have been several megafaunal refugia after about $12,000 \mathrm{BP}$.

\section{ACKNOWLEDGEMENTS}

This work was supported by grants from the Russian RFFI (00-06-80410, 02-04-48458, 03-0680289, 03-05-64434, and 03-05-65252); Institute of Archaeology and Ethnography, Siberian Branch of the Russian Academy of Sciences ("Initial Human Colonization and Settling of Eurasia: Formation and Evolution of Paleolithic Cultures, Correlation of Mechanisms of Cultural Adaptation with Climate Fluctuations"); Presidium of the Russian Academy of Sciences (Fundamental Studies Program "Ethnocultural Interaction in Eurasia"); Governor of the Khanty-Mansiysk Autonomous District; and the UK NERC (GR3/12599). We are grateful to an anonymous reviewer for useful comments.

\section{REFERENCES}

Bronk Ramsey C, Hedges REM. 1999. Hybrid ion sources: radiocarbon measurements from microgram to milligram. Nuclear Instruments and Methods in Physics Research B 123:539-45.

Bronk Ramsey C, Higham TFG, Bowles A, Hedges REM. 2004. Improvements to the pretreatment of bone at Oxford. Radiocarbon, these proceedings.

Bronk Ramsey C, Pettitt PB, Hedges REM, Hodgins GWL, Owen DC. 2000. Radiocarbon dates from the Oxford AMS system: Archaeometry Datelist 30. Archaeometry 42:459-79.

Coplen TB. 1994. Reporting of stable hydrogen, carbon and oxygen isotopic abundances. Pure and Applied
Chemistry 66:273-6.

DeNiro MJ. 1985. Postmortem preservation and alteration of in vivo bone collagen isotope ratios in relation to paleodietary reconstruction. Nature 317(6043): 806-9.

Kuzmin YV, Orlova LA, Zolnikov ID. 2003. Dynamics of mammoth (Mammuthus primigenius Blum.) population in Northern Asia: radiocarbon evidence. In: Reumer JWF, de Vos J, Mol D, editors. Advances in Mammoth Research. DEINSEA (Annual of the Natural History Museum Rotterdam) 9:221-37.

Lõugas L, Ukkonen P, Jungner H. 2002. Dating the extinction of European mammoths: new evidence from 
Estonia. Quaternary Science Reviews 21(6):1347-54. MacPhee RDE, editor. 1999. Extinctions in Near Time: Causes, Contexts, and Consequences. New York: Plenum Press. 384 p.

Martin PS, Klein RG, editors. 1984. Quaternary Extinctions: A Prehistoric Revolution. Tucson, Arizona: University of Arizona Press. 892 p.

Maschenko EN, Pavlov AF, Zenin VN, Leshchinskiy SV, Orlova LA. 2003. The Lugovskoe site: relations between the mammoth assemblage and Late Palaeolithic humas. In: 3rd International Mammoth Conference Program and Abstracts. Occasional Papers in Earth Sciences 5. Whitehorse: Dawson City Museum. p 77 80.

Orlova LA, Kuzmin YV, Dementiev VN. 2004. A review of the evidence for extinction chronologies for five species of Upper Pleistocene megafauna in Siberia. Radiocarbon, these proceedings.

Pavlov AF, Mashchenko EN, Zenin VN, Leshchinsky SV, Orlova LA. 2002. Predvaritelnye rezultaty mezhdistsiplinarnykh issledovanyi mestonakhozhdeniya Lugovskoe (Khanty-Mansiysky avtonomny okrug) [The preliminary results of the multidisciplinary studies of the Lugovskoe locality (Khanty-Mansiysk Autonomous District)]. In: Derevianko AP, Molodin VI, editors. Problemy Arkheologii, Etnografii, Antropologii Sibiri i Sopredelnykh Territoriy. Novosibirsk: Izdatelstvo Instituta Arkheologii i Etnografii SO RAN. p 165-72.

Sher AV. 1997. Late-Quaternary extinction of large mammals in northern Eurasia: a new look at the Siberian contribution. In: Huntley B, Cramer W, Morgan AV, Prentice HC, Allen JRM, editors. Past and Future Rapid Environmental Changes: The Spatial and Evo- lutionary Responses of Terrestrial Biota. BerlinHeidelberg-New York: Springer-Verlag. p 319-39.

Stuart AJ. 1991. Mammalian extinctions in the Late Pleistocene of Northern Eurasia and North America. Biological Reviews of the Cambridge Philosophical Society 66(4):453-562.

Stuart AJ. Forthcoming. The extinction of woolly mammoth (Mammuthus primigenius) and straight-tusked elephant (Palaeoloxodon antiquus) in Europe. Quaternary International.

Stuart AJ, Sulerzhitsky LD, Orlova LA, Kuzmin YV, Lister AM. 2002. The latest woolly mammoths (Mammuthus primigenius Blumenbach) in Europe and Asia: a review of the current evidence. Quaternary Science Reviews 21(7):1559-69.

Sulerzhitsky LD. 1997. Cherty radiouglerodnoi khronologii mamontov Sibiri i severa Vostochnoi Evropy (kak substrata dlya rasseleniya cheloveka) [The features of radiocarbon chronology of mammoths in $\mathrm{Si}$ beria and northern Eastern Europe (as substratum for human dispersal)]. In: Velichko AA, Soffer O, editors. Chelovek Zaselyaet Planetu Zemlya. Moscow: Institut Geografii RAN. p 184-202.

Vasil'chuk Y, Punning J-M, Vasil'chuk A. 1997. Radiocarbon ages of mammoths in Northern Eurasia: implications for population development and Late Quaternary environment. Radiocarbon 39(1):1-18.

Zenin VN, Maschenko EN, Leshchinskiy SV, Pavlov AF, Grootes PM, Nadeau M-J. 2003. The first direct evidence of mammoth hunting in Asia (Lugovskoe site, Western Siberia). In: 3rd International Mammoth Conference Program and Abstracts. Occasional Papers in Earth Sciences 5. Whitehorse: Dawson City Museum. p 152-5. 